\title{
Tools and perspectives for assessing chemical mixtures and multiple stressors
}

\author{
Hans Løkkea,*, Ad M.J. Ragas ${ }^{\mathrm{b}, \mathrm{c}, 1,2}$, Martin Holmstrup ${ }^{\mathrm{a}, \mathrm{d}, 3}$ \\ a Aarhus University, Department of Bioscience, Vejlsøvej 25, P.O. Box 314, DK-8600 Silkeborg, Denmark \\ ${ }^{\mathrm{b}}$ Department of Environmental Science, Institute for Water and Wetland Research, Radboud University Nijmegen, P.O. Box 9010,6500 GL Nijmegen, The Netherlands \\ c School of Science, Open Universiteit, P.O. Box 2960, 6401 DL Heerlen, The Netherlands \\ d Arctic Research Centre, C.F. Møllers Allé 8, bldg. 1110, DK-8000 Aarhus C, Denmark
}

\section{A R T I C L E I N F O}

\section{Article history:}

Received 12 March 2012

Received in revised form 29 October 2012

Accepted 24 November 2012

Available online 10 December 2012

\section{Keywords:}

Chemical mixtures

Natural stressors

Cumulative risk assessment

Dynamic energy budget

Toxicity

NoMiracle

\begin{abstract}
A B S T R A C T
The present paper summarizes the most important insights and findings of the EU NoMiracle project with a focus on (1) risk assessment of chemical mixtures, (2) combinations of chemical and natural stressors, and (3) the receptor-oriented approach in cumulative risk assessment. The project aimed at integration of methods for human and ecological risk assessment. A mechanistically based model, considering uptake and toxicity as a processes in time, has demonstrated considerable potential for predicting mixture effects in ecotoxicology, but requires the measurement of toxicity endpoints at different moments in time. Within a novel framework for risk assessment of chemical mixtures, the importance of environmental factors on toxicokinetic processes is highlighted. A new paradigm for applying personal characteristics that determine individual exposure and sensitivity in human risk assessment is suggested. The results are discussed in the light of recent developments in risk assessment of mixtures and multiple stressors.
\end{abstract} (C) 2012 Elsevier Ireland Ltd. All rights reserved.

\section{Introduction}

\subsection{Background}

Chemical risk assessment has traditionally focused on single stressors. This can partly be explained by the fact that the acute pollution problems of the 20th century were caused by a limited number of chemicals that were emitted in relatively large quantities by a limited number of well-defined sources. Consequently, risk assessments focused on particular substances or sources. The main questions addressed were "Can this substance cause adverse effects?" or "Can this production plant cause adverse effects?" These assessments typically try to capture the chain of events that starts with the emission of a substance into the environment and ends with the emergence of adverse health effects. This approach has been very effective in reducing environmental problems that are caused by single stressors and/or sources, e.g. lead, asbestos and chlorinated insecticides.

\footnotetext{
* Corresponding author. Present address: Harbovad 11, DK-8600 Silkeborg, Denmark. Tel.: +4540318536.

E-mail addresses: hans.lokke@c.dk (H. Løkke), A.Ragas@science.ru.nl, Ad.Ragas@ou.nl (A.M.J. Ragas), mho@dmu.dk (M. Holmstrup).

1 Tel.: +31243653284

2 Tel.: +31455762679.

3 Tel.: +4530183152.
}

Now the overt pollution problems have largely been solved, awareness is growing that exposure to single chemicals is the exception rather than the rule. In everyday life, humans and other living organisms are rarely exposed to single stressors, but to a mixture of different stressors; either concurrently, sequentially, or both. Although researchers and risk assessors have always recognized the need to address this problem, progress has been slow because of lacking knowledge, experimental limitations, and scarce funding (Callahan and Sexton, 2007).

One of the reasons for the growing interest in mixtures and cumulative risks is that some health problems are on the rise without an obvious explanation. It is estimated that $7.4 \%$ of the married women in the USA between 15 and 44 years of age are infertile (Chandra et al., 2005). The diagnoses of autism, attention deficit and hyperactivity disorders (ADD and ADHD) and the prevalence of childhood brain cancer and acute lymphocytic leukemia have all increased over the past 30 years (Jahnke et al., 2005; Trasande and Landrigan, 2004). Air pollution and early life exposure to environmental pollutants are commonly cited as possible causes. Furthermore, a range of health issues is suspected to be related to cumulative stress. For example, neuro-developmental disorders can be caused by heavy metals, dioxins, PCBs and pesticides (Brent, 2004); childhood cancer could be related to a number of physical, chemical and biological agents (e.g. parental tobacco smoke, parental occupational exposure to solvents; Trasande and Landrigan, 2004). As a consequence, several national and international institutions have recognized the need to evaluate risks from mixtures and multiple stressors (NRC, 1994; PCCRARM, 1997; 
Mileson et al., 1999; US EPA, 2000, 2003; ATSDR, 2004; WHO, 2009; European Scientific Committees, 2011).

Cumulative risk assessment can be defined as "an analysis, characterization, and possible quantification of the combined risks to health or the environment from multiple agents or stressors" (US EPA, 2003). The conventional methods for risk assessment of single stressors need to be adapted and extended to deal with the specific challenges posed by mixtures and multiple stressors. This requires new knowledge, e.g. about the complex exposure patterns of individuals and populations, and about the potential interactions between stressors. Novel exposure tools are required that focus on the exposed individual or population, instead of the traditional tools that focus on single substances or pollution sources (Loos et al., 2010a). Measurement data on exposures to mixtures and multiple stressors need to be combined with data on the prevalence of adverse health effects in populations and ecosystems in order to identify potential causal relationships (Rappaport, 2011). Furthermore, methods are needed to predict the effects of concurrent or sequential exposures to mixtures and multiple stressors, preferably based on data from single compounds because these are widely available. We need to understand how and why stressors interact because it is not feasible to test all possible combinations of stressors in the laboratory. Those tests that are necessary need to be performed according to intelligent testing strategies to optimize the use of resources and limit the use of laboratory animals. Collaboration between human and ecological experts in toxicology and risk assessment is desirable because both fields struggle with similar issues and can benefit from each other's strengths (Ragas et al., 2011a). In addition to interactions between chemicals, there are possible interactions with other stressors, such as climate variables (Schlink et al., 2002; Leitte et al., 2009), which need to be addressed.

\subsection{The EU NoMiracle project}

In November 2004, the EU research project NoMiracle was launched (http://www.nomiracle.jrc.ec.europa.eu). The main aim of the project was to gather new knowledge for the improvement of current risk assessment methods and the development of novel methods for cumulative risk assessment. The work was conducted until 30 October 2009. Thirty eight institutions from 17 European countries participated in the project. The consortium consisted of scientists with expertise in human toxicology, epidemiology, aquatic and terrestrial ecotoxicology, risk assessment, environmental chemistry, biochemistry, toxicogenomics, physics, mathematical modeling, geographical informatics, and social and economic sciences. Box 1 shows the main goals of the NoMiracle project. The themes of NoMiracle were rather broad, allowing for interdisciplinary collaboration.

The project resulted in more than 200 scientific reports and 200 peer-reviewed papers covering a large diversity of topics such as the identification of exposure scenarios, sorption behavior of substances, environmental degradation, analytical methods, fate modeling, toxicokinetics, mixture toxicity, effects of multiple stressors, in vitro test systems, probabilistic risk assessment methods, exposure modeling, risk perception and risk visualization. Six open international workshops and conferences were held. An international workshop on mixture toxicity was organized together with the Society of Environmental Toxicology and Chemistry (SETAC) and resulted in a book on mixture toxicity (Van Gestel et al., 2010). The main results of the NoMiracle project were published as a special issue of Science of the Total Environment (Løkke et al., 2010). The new methods and models that were developed are publicly available in the NoMiracle Tool Box (http://www.nomiracle.jrc.ec.europa.eu/Lists/Toolbox/).

\section{Box 1}

Goals of the EU NoMiracle project.

1. To develop new methods for assessing the cumulative risks from combined exposures to several stressors including mixtures of chemical and physical/biological agents.

2. To achieve more effective integration of the risk analysis of environmental and human health effects.

3. To improve our understanding of complex exposure situations and develop adequate tools for sound exposure assessment.

4. To develop a research framework for the description and interpretation of cumulative exposure and effect.

5. To quantify, characterise and reduce uncertainty in current risk assessment methodologies, e.g. by improvement of the scientific basis for setting safety factors.

6. To develop assessment methods which take into account geographical, ecological, social and cultural differences in risk concepts and risk perceptions across Europe.

7. To improve the provisions for the application of the precautionary principle and to promote its operational integration with evidence-based assessment methodologies.

The present paper summarizes the most important insights and findings of the EU NoMiracle project within three major fields of the project, namely: (1) risk assessment of chemical mixtures, (2) combinations of chemical and natural stressors, and (3) the receptor-oriented approach in cumulative risk assessment. The results of the NoMiracle project are discussed in the light of recent developments in risk assessment of mixtures and multiple stressors. The paper concludes with an outlook for the future and a number of research and policy recommendations.

\section{Risk assessment of chemical mixtures}

\subsection{Mixture experiments}

The NoMiracle consortium set up a series of (eco)toxicity tests with chemical mixtures. The chemicals were taken from a priority list that focused on metals, polyaromatic hydrocarbons (PAHs) and specifically acting pesticides (e.g. organophosphate and neonicotinamide pesticides). Species used for testing included the Vibrio fischeri Microtox ${ }^{\mathrm{TM}}$ system, Tubifex tubifex, chironomidae, Danio rerio, Daphnia magna, Mytilus galloprovincialis, Lumbricus rubellus, Folsomia candida, Caenorhabditis elegans, carabid beetles and human cell lines (human A549 cells and Jurkat cells) including existing and custom generated reporter cell lines. Measured endpoints included cellular change, weight change, cell proliferation, reproduction, growth and viability (Oostingh et al., 2008, 2009; Röder-Stolinski et al., 2008a,b).

The underlying idea was to explore the application range of two predictive models for the joint effects of two or more substances, i.e. concentration addition (CA) and independent action (IA), and deviations from these descriptive models, including greater than additive or less than additive toxicity, dose level or dose ratio dependent deviations. The broad applicability of these two reference models has been demonstrated for both similarly acting (Altenburger et al., 2000; Deneer et al., 1988a; Faust et al., 2001; Hermens et al., 1985; Howard et al., 2010) and independently acting compounds (Backhaus et al., 2000; Deneer et al., 1988b; Faust et al., 2003). Data on the performance of these models can serve multiple purposes. First, it can be used to assess the probability that the two reference models fail to correctly describe the joint effects of chemicals, which is relevant information for risk assessors, e.g. when deriving a safety factor for mixture toxicity. Second, 
exploration of those cases that deviate may reveal patterns leading to a better mechanistic understanding of mixture effects. For example, it could be investigated whether deviations are conserved over different taxonomic groups or endpoints, and which contaminant groups and stressors show the greatest propensity for deviations.

Ultimately, NoMiracle generated a database of a 322 experimental data-sets, i.e. 144 studies with ecotoxicological test species and 178 with human cell lines (e.g. Gomezeyles et al., 2009; Loureiro et al., 2010; Martin et al., 2009). A preliminary analysis of the ecotoxicological data with an updated version of the MixTox model (Jonker et al., 2005) indicated that 94 mixtures (65.3\%) had significant interaction, i.e. greater than additive (16.0\%), less than additive (17.3\%), dose-level dependent deviation (16.0\%) and dose ratio dependent deviation (16.0\%). These numbers are in good agreement with previous studies. For example, Cedergreen et al. (2008) found interactions in $50 \%$ of the cases included in a separate mixture effect program, and Warne (2003) reported 20-30\% nonadditive cases based on a review of ecotoxicological mixture studies. The significance of the observed deviations from the CA and IA models is discussed in Section 5.

Creation and exploration of the NoMiracle mixture database proved more difficult than originally anticipated. The mixture experiments took more time and the researchers wanted to publish their results before inclusion in a database. As a result, the database was incomplete and only preliminary analyses could be performed. The partners are currently looking for fundings to further extend the database because it has huge potential, e.g. to explore the magnitude of the deviations and compare the results with data from Ross (1996) and Ross and Warne (1997) who reported that 5\% of the mixtures included in a review differed more than a factor of 2.5 from CA, and $1 \%$ differed more than a factor of 5 . This type of data could be used to derive a safety factor for mixture toxicity. Other potential applications of the database include: (1) verification whether interactions at low dose levels are occurring or toxicologically insignificant, or not (European Scientific Committees, 2011); (2) verification whether the range of deviation from additivity decreases as the number of components in a mixture increases (Warne and Hawker, 1995); (3) explore whether data about metabolic interactions can be used to predict mixture toxicity (Ragas et al., 2011b).

\subsection{Mechanistic mixture studies}

Mixture experiments can provide an indication of the joint effects of substances, but it is practically infeasible to test all mixture combinations. The number of possible substance combinations is sheer endless and the dose-response relationship of a certain combination is likely to depend on the dose ratios. Therefore, a mechanistic approach to assessing mixture risk is highly desirable. If the most important mechanisms involved in mixture toxicity can be identified and described, this knowledge can be used to improve the prediction of mixture risks.

To provide a basis for interpreting the mechanisms involved in mixture toxicity, a biologically based framework was developed (Fig. 1; Spurgeon et al., 2010). The framework consists of three phases: the external exposure phase, the toxicokinetic phase and the toxicodynamic phase. The first phase involves interactions in environmental media that may influence the external dose of one or more chemicals, and includes processes such as speciation, binding and transport (Spurgeon et al., 2011). The second phase involves interactions inside the organism that influence the internal dose of one or more chemicals and includes processes such as absorption, metabolism and elimination (Svendsen et al., 2011). The last phase involves interactions at the target site that may modulate the toxic impact of one or more substances (Svendsen et al., 2011). Once the nature and type of potential interaction has been established, designing experimental approaches that can investigate the underlying mechanisms is made easier.

The framework in Fig. 1 built as a background for the mechanistic mixture studies in NoMiracle (e.g. Dimitrov et al., 2005; Dimitrova et al., 2010; Dorne, 2007; Vandenbrouck et al., 2009). Part of the work focused on the development of a process-based approach for describing and predicting mixture effects (Baas et al., 2010a) based on the theory of dynamic energy budgets (DEBs) (Kooijman, 2009). The approach considers toxicity as a process over time that depends on (1) the buildup of the internal concentration which is modeled using a one-compartment model, and (2) a hazard model that describes the adverse effect as a chance process, e.g. using a killing rate. The mixture effect is build up from the effects of the individual components and all possible binary interactions in the mixture. The approach results in a mathematical model that consists of three parameters per compound (the no effect concentration, an elimination rate and an effect rate), a control effect rate for the experiment (to account for the effect rate in the unexposed control group) and one interaction parameter for each pair of compounds. The parameter values can be determined by fitting the model to a time series of toxicity data, e.g. data on survival. The model has shown good performance in several case studies, e.g. modeling the effect of binary metal mixtures on survival of the soil arthropod F. candida (Baas et al., 2007) and modeling the effect of a mixture of 14 PAHs on the survival of the fish Pimephales promelas (Baas et al., 2009a). The model was also used to predict the effect of surface waters contaminated with over 90 chemicals on the survival of D. magna (Baas et al., 2009b). In 34 out of 37 cases (92\%), daphnid survival was predicted correctly.

The approach can be considered a step forward compared to the conventional CA and IA models because it has a mechanistic basis and considers uptake and toxicity as processes in time (Baas et al., 2010b). Consequently, the model uses relatively few parameters which actually have a biological meaning (e.g. killing and elimination rates). Furthermore, the model is less sensitive to random variations because the entire data-set is fitted to the model, whereas the CA and IA models have to be fitted separately for each moment in time. The approach has considerable potential for describing and predicting mixture effects, but requires the measurement of toxicity endpoints at different moments in time. The extra costs of performing toxicity measurements in time come with the promise of an increased understanding of the underlying biological mechanisms and prediction of mixture effects.

\section{Combinations of chemical and natural stressors}

In real-world environments it is not unusual for organisms and humans to be exposed to several stressful factors of natural origin besides those of polluting chemicals. These natural factors may in aquatic ecosystems include anoxia and $\mathrm{pH}$ changes which have serious consequences for many species (Hoegh-Guldberg et al., 2007). In the terrestrial environment extreme climatic conditions, such as heat waves, drought, flooding or extreme cold are also important stressors. With current concerns over global climate changes predicted to increase the frequency and amplitude of extreme weather events (IPCC, 2007) it is important to include interactions between multiple stressors in modern risk assessment procedures. Effects of chemical pollution may interact with the effects of these natural abiotic stressors (Laskowski et al., 2010; Heugens et al., 2001; Gordon, 2001). In addition, biotic stressors such as parasites and pathogens may interact with environmental toxicants (Holmstrup et al., 2010). This also applies to humans since environmental toxicants may compromise the human immune system (Oostingh et al., 2008). In the NoMiracle project, it has been found that several of the chemicals tested had a clear immunomodulatory effect at non 


\section{Outside organism}

Inside organism

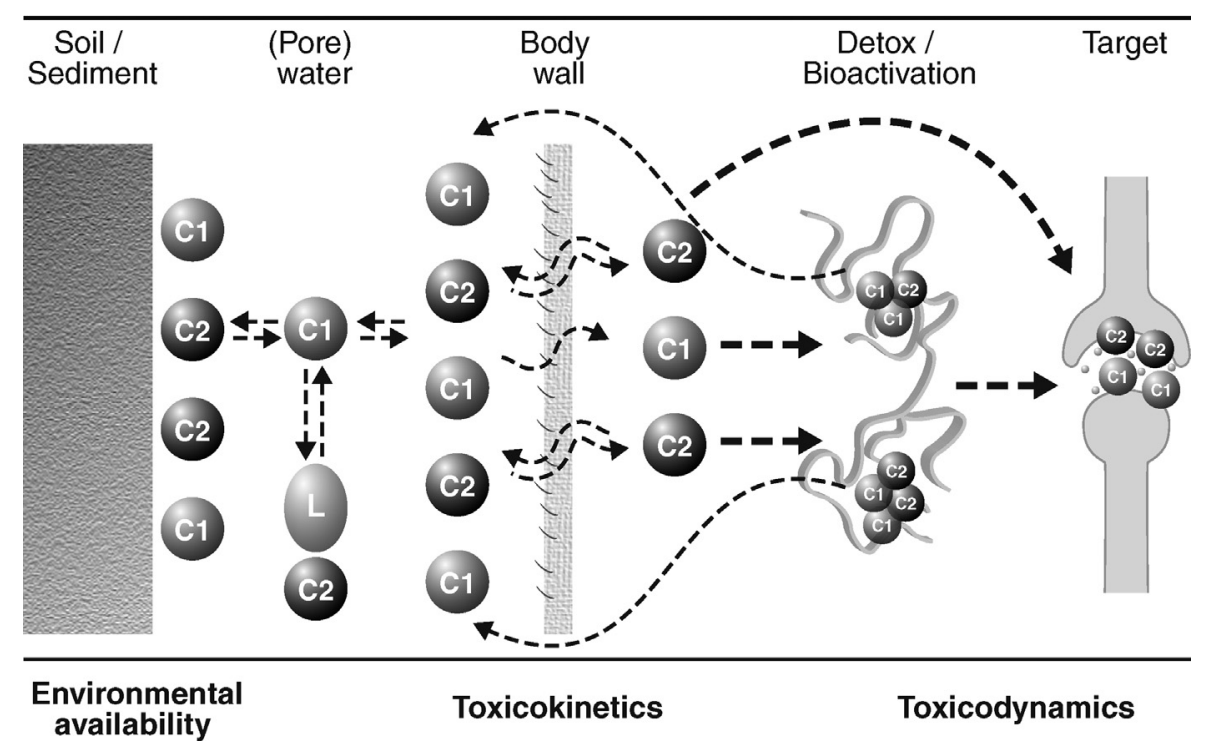

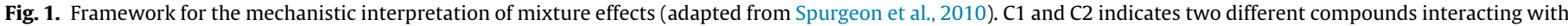
soil particles, biological macromolecules or structures, and ligands (L) in a mixture situation.

cytotoxic concentrations (Holmstrup et al., 2010). This suggests that an activated immune system can be more prone to react with environmental toxicants and that the concentrations of pollutants that might have an impact on human health are lower when the person exposed is ill.

The approach used in studies of multiple stressors (natural and chemical) is based on the same conceptual framework as outlined for mixture effects in Fig. 1. Natural factors can influence the bioavailability of chemicals in many ways (left side of Fig. 1). Examples include water chemistry, which can alter the bioavailability of heavy metals in aquatic ecosystems (Weber et al., 1992; Santore et al., 2002), and air humidity influencing the occurrence of airborne particles, which in turn may have an effect on the prevalence of chronic bronchitis among people in areas with heavy air pollution (Leitte et al., 2009). The list of examples in the literature is extensive (see for example review by Heugens et al., 2001), but at present these issues are only included to a limited extent in risk assessment procedures despite their apparent importance. Toxicokinetics may also be drastically influenced by environmental factors. A prime example is temperature, which may both influence the active uptake and elimination rate of toxicants, but this primarily applies to poikilothermic organisms where metabolism is directly coupled to temperature (but see also review by Gordon, 2001). On the one hand, poikilothermic organisms such as insects are often more active at higher temperatures and may thus take up more of a toxicant (e.g. insecticides) than at low temperature where activity is depressed. On the other hand, metabolism and detoxification processes may run faster at the higher temperatures (Talent, 2005). Andersson and Förlin (1992) reviewed studies on biotransformation of organic hydrocarbons (e.g. PAHs) in fish and concluded that induction and efficiency of the cytochrome P450 system is highly dependent on ambient temperature, although no consistent pattern due to either rising or declining temperature was found. However, these examples highlight the importance of environmental factors on toxicokinetic processes.

Last, but not least, interactions between effects of natural stressors and effects of toxicants can occur at the target receptor, or more broadly spoken, at the physiological level (right-hand side of Fig. 1). Results of the NoMiracle project have shown that greater than additive effects are not unusual when organisms are exposed to combinations of natural stressors and toxic stressors, especially when the natural stressor reaches extreme levels; a review of more than 140 studies showed that about $50 \%$ of studies on invertebrates revealed some degree of greater than additive interactions taking place (Holmstrup et al., 2010; Laskowski et al., 2010). For example, sublethal concentrations of copper, which is a widespread terrestrial contaminant, can completely destroy the ability of earthworms to withstand frost or drought (Bindesbøl et al., 2005; Fisker et al., 2011). Other contaminants may significantly reduce the drought tolerance of soil organisms such as Collembola (Højer et al., 2001; Holmstrup, 1997; Skovlund et al., 2006). Screenings of several environmental contaminants suggest that pollutants where the mode of action is connected with membrane stability and functioning (e.g. copper, non-ionic detergents, and several PAHs) can reduce the drought and cold tolerance of poikilothermic animals (Holmstrup et al., 2010). As a corollary to this it can be argued that cold and drought can increase the negative effects of environmental pollutants. The main reason for this interaction may be that such pollutants cause changes in the composition of membrane phosholipids via oxidative stress and lipid peroxidative processes, altering the physical properties of the membranes (Bindesbøl et al., 2009), or merely change the physical properties of cellular membranes by their presence in, and interactions with the lipid matrix (Ogunbayo et al., 2007; Van Wezel et al., 1996; Jørgensen et al., 1991). Both phenomena may potentially compromise membrane functionality with respect to challenging osmotic or thermal conditions. However, published research in this area is still mainly of a phenomenological and descriptive character; documented mechanistic and molecular understanding remains to be provided.

It is obvious that organisms in the environment and humans are well adapted to harsh environmental conditions, and thus significant interactions with toxicants are likely a rather stochastic phenomenon that does not occur on a regular basis. However, it seems reasonable to conclude that situations can arise that are potentially causing so large effects that risk assessment should somehow account for these situations. As an example, the European heat wave in 2003 caused significant increase in mortality especially in the French population. It is not known how much of this extra mortality was related to simultaneous pollution problems, but it illustrates that under severe stress humans and other 

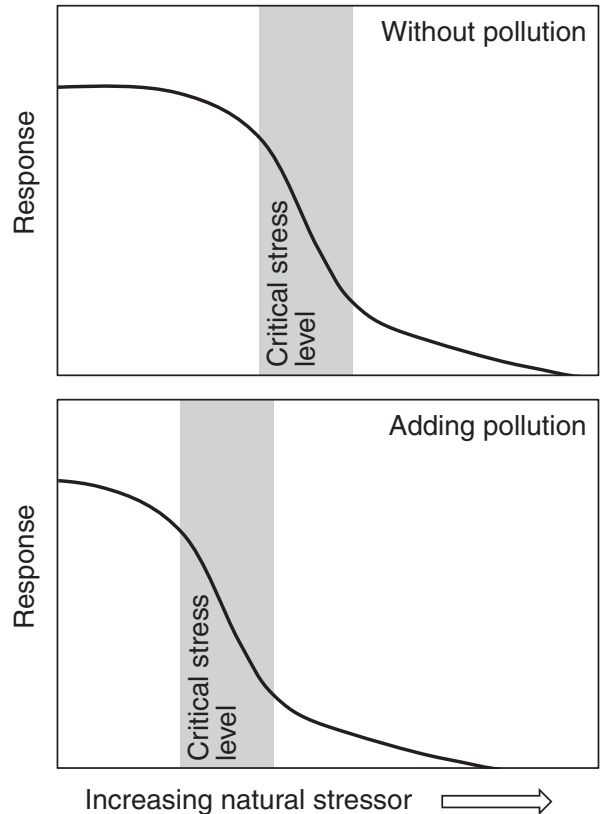

Fig. 2. Performance of an organism is related to natural stress factors ("stressors") in a normal dose-response relationship. For all stressors, organisms are able to compensate for deleterious effects until a certain "critical stress level" is reached; at higher levels performance declines (upper panel). If additional stressors such as pollution is added to the system, the critical stress level may be shifted to the left (lower panel) indicating that pollution has made the organism less tolerant toward the natural stressor.

organisms may become more susceptible to other types of stress than they usually are (Fig. 2).

Compared with human risk assessment, it is more common in ecological risk assessment to include natural stressors. Thus, the European Marine Strategy Framework Directive (MSFD, 2008) takes into account the structure, function and processes of the constituent marine ecosystems together with natural physiographic, geographic, biological, geological and climatic factors, as well as physical, acoustic and chemical conditions, including those resulting from human activities. In a similar way the European Framework Directive by monitoring a range of biotic communities potentially addresses complex mixtures of stressors in very different regions and water body types (Hering et al., 2010).

\section{The receptor-oriented approach}

Risk management aims to control events that can result in adverse effects in humans or ecosystems. In the case of single chemicals, these events can be presented by a single chain, starting with the production and emission of the chemical of concern and ending with the adverse effects (Fig. 3). When the relationships between the links of the chain are known, data and measures relating to one link can be translated relatively easily into implications for other links. This explains why traditional risk assessment often focuses on substances or sources.

In the case of multiple stressors, the events that lead to adverse effects can no longer be presented by a single chain, but multiple chains are necessary that converge at the receptor, i.e. the individual, population or (eco)system that is being exposed (Fig. 3). The branched nature of this chain implies that data and measures relating to one link can no longer be easily translated into implications for other links. There is a strong impetus to focus on the receptor as an integrator of exposure and effects over space and time. The question is no longer "How does this substance or source influence public health or ecosystems?", but "How are public health and ecosystems influenced by the mixture of stressors they are being exposed to?". Within the NoMiracle project it was concluded that cumulative risk assessment requires a paradigm shift from the traditional stressor- and source-oriented assessments toward receptor-oriented assessments. This paradigm shift has some serious implications for the way exposure and effects are assessed and requires a broader regulatory context than currently provided. These issues are discussed in more detail below.

\subsection{Exposure assessment}

An important challenge in receptor-oriented exposure modeling is the description of the activity pattern of the receptors, including movement. Two approaches can be distinguished, i.e. a
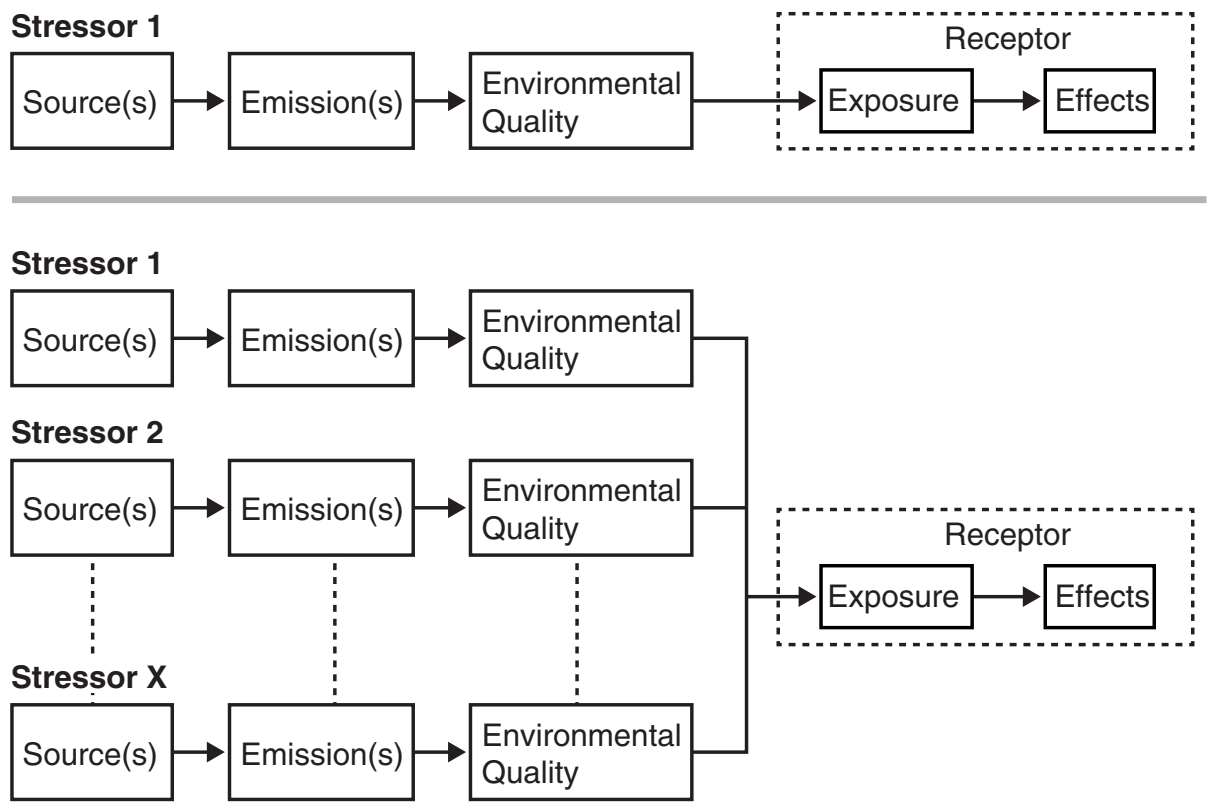

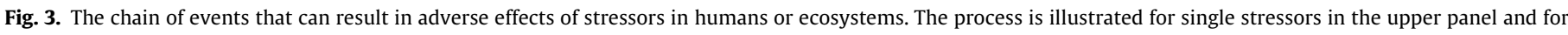
multiple stressors in the lower panel. 
descriptive and a predictive approach. In the descriptive approach, data about activity patterns are gathered, stored in a database and subsequently used for modeling exposure. This approach is typical for human exposure models such as Lifeline ${ }^{\mathrm{TM}}$ (The Lifeline Group Inc., 2007), CARES (ILSI, 2008), SHEDS (Zartarian et al., 2006, 2007) and TRIM.Expo/APEX (US EPA, 2006a,b). Important strengths of the descriptive approach are the simulation of realistic activity and movement patterns and the preservation of correlations between different activities. However, the exposure predictions only apply to the conditions reflected in the database. The approach does not account for changes that may influence the activity patterns such as the introduction of a new transport system or a new food product on the market.

In the predictive approach, activity patterns are modeled using behavioral rules such as the preference of a species for a certain habitat or for a certain type of food. This approach is typical for wildlife exposure models such as $\mathrm{SE}^{4} \mathrm{M}$ (Hope, 2005), ALMaSS (Topping et al., 2003) and EcoSpace (Loos et al., 2010b). These models use object-oriented programming techniques to simulate interactions between organisms and between organisms and the environment. An important strength is the large explanatory power of these models, i.e. the activity pattern is an emergent property that depends on the characteristics of the receptor, environment and behavioral rules. However, the accuracy of the predictions strongly depends on the quality of the behavioral rules which rarely have been validated.

Loos et al. (2010a) compared five human and five wildlife receptor-oriented exposure models. They concluded that human models can act as a source of inspiration for wildlife models when it comes to the compilation and use of data on activity patterns. A nice example is a recent Dutch study on the foraging behavior of the eagle owl (Bubo bubo), which unexpectedly revealed that these birds spend an important part of their time foraging in the city of Maastricht (Houben, 2011). This results in an entirely different exposure pattern than would be predicted with random behavioral algorithms. Loos et al. (2010a) furthermore suggested that wildlife models can serve as a source of inspiration for human models when it comes to the simulation of emergent activity patterns. This suggestion was taken up by Schlink and Ragas (2011) who compared different algorithms to simulate human movement in urban areas. Of the algorithms tested, truncated Lévy flights (TLFs) and agendabased walks performed best because they provide conditions for individual-specific trajectories and exposure. They demonstrated the plausibility of their results for exposure to airborne benzene and the combined exposure to benzene and nonane.

We conclude that cumulative risk assessment requires further development of receptor-oriented exposure models. Important issues to address include (1) gathering of measurement data on activity and movement patterns, (2) development of reliable algorithms to simulate activity patterns and movement, (3) maintenance of correlations between different activities, and (4) further development and application of object-oriented programming techniques in exposure modeling.

\subsection{Effect assessment}

Challenges in receptor-oriented effect assessment include (1) exploration of the impact of temporal variations in exposure regimes, and (2) inclusion of receptor characteristics in effect assessment. Receptor-oriented exposure models typically result in a graph that reflects the variation in exposure(s) over time. This triggers the question how to deal with temporal variations in exposure(s). Most toxicity tests are performed under constant exposure conditions. Extrapolation to time-variant exposures is relatively simple for substances that accumulate or for which the effect accumulates, but can be more problematic for acute toxicants.
This requires a good understanding of the toxicokinetic processes involved. It becomes even more complicated when different stressors are involved, because the order of the different exposures may affect the outcome. It is remarkable how little systematic knowledge is available about the impact of time-variable exposure conditions, especially in relation to different stressors (e.g. Johnson et al., 1990; Kimizuka et al., 1987; Kimizuka and Hayashi, 1993). Here lies an enormous challenge for the future. The homogeneous exposure regimes currently applied in toxicity tests will have to be extended to include the effects of the time-variable and sequential exposures that occur in real life. Some data on sequential exposure are available e.g. from studies in carcinogenesis (Kortenkamp et al., 2009). Only very few environmental studies have been conducted using sequential exposure, e.g. Drost et al., 2003; Vallotton et al., 2009 , focussing on pulse exposure of algae to herbicides.

The sensitivity of individuals for a stressor typically varies within a population. When deriving a safe exposure level for a population, this inter-individual variability is traditionally addressed by applying a safety or assessment factor (Dorne, 2010). The resulting value aims to protect sensitive individuals within the population. This approach is suitable for single stressors, but seems less suitable for multiple stressors. For one reason, the approach will result in overly conservative risk assessments when the sensitivities for different stressors are uncorrelated (Price et al., 2009). However, when sensitivities are correlated, as is the case for substances that are metabolized by the same metabolic pathway, the approach is appropriate. This issue could be addressed by including the personal characteristics that determine individual sensitivity in the effect assessment. The receptor-oriented approach provides a perfect platform to realize this. Several large scale studies are currently being performed in which individual data on activity patterns, chemical exposures, personal characteristics (e.g. ethnicity, socio-economic status and genetic profile) and health status are gathered in a coherent way, e.g. the National Children's Study in the USA (http://www.nationalchildrensstudy.gov/). These studies will provide a wealth of information that will enable the integrated modeling of exposure and effects in a truly receptororiented approach. With this type of approach it should be possible to identify more realistic combinations of activity patterns and personal characteristics that result in high risks for single as well as multiple stressors.

\subsection{Regulatory context}

In the human health area, mixture issues are often addressed based on legislation and regulations that either focus on (individual) substances or compartments. For example, widely used common mixtures such as PAHs and PCBs are evaluated within the context of substance-specific regulations such as the Toxic Substances Control Act (TSCA) in the USA and the REACH program in the EU. Mixtures encountered at polluted sites are evaluated within the context of regulations such as Comprehensive Environmental Response, Compensation, and Liability Act (CERCLA) in the USA dealing with improperly deposited wastes, and the Water and Soil Framework Directives in the EU. These regulations do allow for assessment of mixture risks, but the problem definition is generally limited to a single compartment or a common mixture, e.g. exposure to contaminated soil or to PAHs. However, the nature of mixture and cumulative risks can be much broader, e.g. a farmer who works with pesticides and lives on a metal-polluted soil in a house with high radon exposure levels. Indeed, it is interesting to note that comprehensive regulations to protect human health against the potential effects of sequential or concurrent exposure to multiple stressors are currently lacking. The identification and regulation of mixture risks requires a broader regulatory context than currently covered by most regulations. The focus should not 
be on a specific substance, mixture or compartment, but on the integrated protection of human or ecological receptors from exposure through different routes and at different moments in time.

Contrary to the human health area, legislation concerning the protection of ecosystems and wildlife is much more integrative. The focus is on protection of the receptor against different types of stressors. Mandated by acts like the Endangered Species Act (ESA) and the Marine Mammal Protection Act (MMPA), governmental agencies such as the US Environmental Protection Agency are required to assess risks to ecosystems and wildlife populations resulting from exposure to anthropogenic stressors in the broadest definition (e.g. agricultural and urban land use, introduced invasive and exotic species, nutrient enrichment, direct human disturbance, and toxic chemicals; Munns, 2006). These regulatory laws promote risk assessment to consider both chemical and other (physical and biological) stressors.

\section{Discussion}

The NoMiracle project covered a broad field. In this review we have focused on three important topics for the assessment of risks associated with multiple stressors, namely the need for novel tools for (1) risk assessment of chemical mixtures, (2) combinations of chemical and natural stressors, and (3) the receptor-oriented approach in cumulative risk assessment.

Within the risk assessment of chemical mixtures, there is much discussion on the occurrence and frequency of nonadditive effects, defined as deviations from a simple additive model. Recently Boobis et al. (2011) analyzed key studies from 1990 to 2008 relating to greater than additive interactions in mammalian test systems at low doses. Of 90 studies, they identified 6 studies that provided useful quantitative estimates of greater than additive effects at low doses, and the predicted deviations from additive models were less than a factor of 4 . Within ecotoxicology, a higher frequency of deviations is reported. As a rule of thump the frequency seems to lay in the interval of 20-65\% (Cedergreen et al., 2008; Jonker et al., 2005; Warne, 2003). The deviations were in the same order (a factor of 2-5) as found by Boobis et al. (2011).

These deviations were found using the CA and IA models with concentrations at relatively high dose levels. In the NoMiracle project, the use of the CA and IA models gave rise to concern when analyzing ecotoxicological data from studies with measurements at intermediate time points. Such data sets are rare, however. Baas et al. (2007) reported a study on the survival of springtails (F. candida) which were exposed to binary mixtures of metals. Depending on the time of observation, deviations from the study with copper and cadmium using the CA model changed between significant greater than additive effects, dose level dependent effects greater than additive, dose ratio dependent interaction and no interaction. At one time point and at high doses, less than additive effects were observed. The analysis by use of the IA model showed greater than additive effects at all time points. By analyzing the same data with the newly developed process-based model using the DEB theory, the authors showed excellent agreement between measured and calculated survival data. Only in the case of a mixture of copper and lead was a slight less than additive effect found; the other mixtures showed no interaction. The authors concluded that when models do not incorporate time, it is impossible to speak of interaction in the mixture because the interaction depends on the time point that is considered. This conclusion has been underpinned by a series of experiments (Baas et al., 2009a,b, 2010a,b; Jager et al., 2010).

The lesson learned from the NoMiracle project on simple addition models such as the CA and IA models is that they may be useful for screening purposes and for analysis of groups of chemicals with similar mode of action. However, the time factor may be crucial for a proper assessment, in particular in cases of sequential exposure. The models based on DEB theory have the basic assumption that toxicants must be taken up by the organism before they can exert an effect. The internal concentration determines the effect, and once it is built up above a certain threshold level effects start to show. This threshold level is defined as the NEC (the no effect concentration). It has been shown that the NEC is shared by toxicants having the same mode of action as for example PAHs causing baseline toxicity (Baas et al., 2010c). This allows for reduction in experimental effort in assessing effects of mixtures, extrapolation to other mixtures, other points in time, or in a wider perspective to other organisms.

When dealing with the impact of multiple stressors, the assessment is most often restricted to chemical mixtures. The reason is obviously that it is more complicated to deal with natural stressors, and no approved methods are at hand. Given that exposure to multiple chemicals from different sources via multiple routes is beyond the scope of present regulations, it is far more distant to include natural stressors. However, it is problematic to ignore the natural stressors if one wants to unravel the causes of increased rates of disease or adverse environmental impacts that may be wholly or partially caused by chemical substances. In many cases, the interactions between natural and anthropogenic influences need to be examined. For human health, obvious examples are the interactions of exposure to chemicals in daily life and the work environment with natural stressors such as diseases, biologically active components in food, UV radiation, alpha particles from radon or exposure to gamma-radiation. In the environment, natural stress factors are often more important and widespread than stress from chemical pollution, which is typically rather local and related to industrial or agricultural activities (e.g. Kozlov and Zvereva, 2007). Natural stressors are particularly important in extremely hot, cold or dry environments such as the polar regions, or deserts, where organisms and humans must cope with recurring climatic stress (Wharton, 2002), but the global changing of climate and increased occurrence of extreme weather events such as heat waves (IPCC, 2007) will also increase the risk from combined effects of pollution and natural stress factors. Our point is that effects of natural stressors can be amplified by interaction with the chemicals.

During the recent years, the question of how to manage the risk from multiple chemicals has come into focus. There are no generally applicable guidelines as to when assessment of combinations of chemicals should be carried out. In part this is due to the assumptions that substantial effects due to exposure to a combination of chemicals are uncommon (European Scientific Committees, 2011). The EU Advisory Committees concluded that for chemicals with different modes of action (i.e. acting independently), no robust evidence is available that exposure to a mixture of such substances is of health concern if each individual chemical is present at or below their no effect levels. They recommend an approach for the assessment of chemical mixtures which emphasizes the need for information on the mode of action, but the decision algorithm comes to a stop if the Threshold of Toxicological Concern for single substances is not exceeded. This approach may be questioned in cases where chemicals modify the absorption of others (e.g. skin penetration enhancing substances in cosmetics) or chemicals competing for active transport mechanisms (uptake, clearance). Independently acting chemicals in a mixture may also modify the metabolism of other mixture components, e.g. if two or more substances are metabolized by the same enzyme, thereby enhancing the effect of single compounds at the Threshold of Toxicological Concern.

Within the WHO and IPCS a framework has been developed for risk assessment of combined exposure to multiple chemicals using a tiered approach (Meek et al., 2011). This framework builds on previously published guidance for priority setting and assessment 
of combined exposures (e.g. US EPA, 2007). There is a gradual transition from the risk assessment of single compounds to multiple compounds by multiple routes (European Scientific Committees, 2011), to multiple compounds by multiple routes taking individual variation into consideration (US EPA, 2007), and finally to the receptor-oriented approach (see Section 4). By the receptororiented approach the individual is assessed for the total effect of multiple stressors, i.e. not only low doses of pollutants. For example, current risk assessment is concerned with traces of pharmaceutical drugs in drinking water, while an often long-lasting exposure to medical products is overlooked. In the use of drugs, the emphasis is usually on the benefits and to a lesser degree on the side effects, and rarely on interactions with xenobiotics. In a similar way, the interactions of xenobiotics with deposits of persistent organic compounds in human fat, radon radiation, tobacco smoke, alcohol and toxic food components are not accounted for. There are ethical, political and practical reasons not to include these major impact factors. However, to understand the occurrence and even increase in frequency of a series of chronic diseases and the role of xenobiotics, the whole picture needs to be taken into account.

Future testing for mixture effects will take advantage of the ongoing revolution in biology and biotechnology. In NoMiracle, studies on the potential for using omics in the assessment of chemical mixtures was initiated by use of marine animals, e.g. by Dondero et al. (2010) and Dorne (2010). Within human biology, new methods are being developed that use biological data in order to find biochemical pathways that are relevant to the different responses of an organism to different conditions. Biochemical pathways, instead of being treated as just sets of genes, are viewed as a network of interactions between proteins or metabolites (Thomas et al., 2009). By this approach, the identification of key regulatory pathways that integrate genetic and environmental modulators defines disease associated targets that will allow for efficient screening of large numbers of environmental factors (Gohlke et al., 2009). Such novel methods and approaches are anticipated to play a major role in future risk analyses of multiple stressors by multiple routes using a receptor-oriented approach.

\section{Conflict of interest}

None.

\section{Funding source}

EU FP6 integrated project NoMiracle Contract No. 003956.

\section{Acknowledgements}

The studies were supported by the EU 6th Framework program for Research and Technological Development under the Integrated Project NoMiracle (Novel Methods for Integrated Risk assessment of Cumulative Stressors in Europe; http://nomiracle.jrc.it), Contract No. 003956.

\section{References}

Andersson, T., Förlin, L., 1992. Regulation of the cytochrome P450 enzyme system in fish. Aquat. Toxicol. 24, 1-19.

Altenburger, R., Backhaus, T., Boedeker, W., Faust, M., Scholze, M., Grimme, L.H., 2000. Predictability of the toxicity of multiple chemical mixtures to Vibrio fischeri: mixtures composed of similarly acting chemicals. Environ. Toxicol. Chem. 19, 2341-2347.

ATSDR (Agency for Toxic Substances and Disease Registry), 2004. Guidance Manual for the Assessment of Joint Toxic Action of Chemical Mixtures. US Department of Health and Human Services, Atlanta.

Baas, J., Jager, T., Kooijman, S., 2009a. A model to analyze effects of complex mixtures on survival. Ecotoxicol. Environ. Saf. 72, 669-676.
Baas, J., Jager, T., Kooijman, S., 2010a. A review of DEB theory in assessing toxic effects of mixtures. Sci. Total Environ. 408, 3740-3745.

Baas, J., Jager, T., Kooijman, S., 2010b. Understanding toxicity as processes in time. Sci. Total Environ. 408, 3735-3739.

Baas, J., Stefanowicz, A.M., Klimek, B., Laskowski, R., Kooijman, S., 2010c. Modelbased experimental design for assessing effects of mixtures of chemicals. Environ. Pollut. 158, 115-120.

Baas, J., Van Houte, B.P.P., Van Gestel, C.A.M., Kooijman, S., 2007. Modeling the effects of binary mixtures on survival in time. Environ. Toxicol. Chem. 26, 1320-1327.

Baas, J., Willems, J., Jager, T., Kraak, M.H.S., Vandenbrouck, T., Kooijman, S.A.L.M., 2009b. Prediction of daphnid survival after in situ exposure to complex mixtures. Environ. Sci. Technol. 43, 6064-6069.

Backhaus, T., Altenburger, R., Boedeker, W., Faust, M., Scholze, M., Grimme, L.H., 2000. Predictability of the toxicity of a multiple mixture of dissimilarly acting chemicals to Vibrio fischeri. Environ. Toxicol. Chem. 19, 2348-2356.

Bindesbøl, A.M., Bayley, M., Damgaard, C., Hedlund, K., Holmstrup, M., 2009. Changes in membrane phospholipids as a mechanistic explanation for decreased freeze tolerance in earthworms exposed to sublethal copper concentrations. Environ. Sci. Technol. 43, 5495-5500.

Bindesbøl, A.M., Holmstrup, M., Damgaard, C., Bayley, M., 2005. Stress synergy between environmentally realistic levels of copper and frost in the earthworm Dendrobaena octaedra. Environ. Toxicol. Chem. 24, 1462-1467.

Boobis, A., Budinsky, R., Collie, S., Crofton, K., Embry, M., Felter, S., Hertzberg, R., Kopp, D., Mihlan, G., Mumtaz, M., Price, P., Solomon, K., Teuschler, L., Yang, R., Zaleski, R., 2011. Critical analysis of literature on low-dose synergy for use in screening chemical mixtures for risk assessment. Crit. Rev. Toxicol. 41, 369-383.

Brent, R.L., 2004. Environmental causes of human congenital malformations: the pediatrician's role in dealing with these complex clinical problems caused by a multiplicity of environmental and genetic factors. Pediatrics 113, 957-968.

Callahan, M., Sexton, K., 2007. If cumulative risk assessment is the answer, what is the question? Environ. Health Perspect. 115, 799-806.

Cedergreen, N., Christensen, A.M., Kamper, A., Kudsk, P., Mathiassen, S.K., Streibig, J.C., Sorensen, H., 2008. A review of independent action compared to concentration addition as reference models for mixtures of compounds with different molecular target sites. Environ. Toxicol. Chem. 27, 1621-1632.

Chandra, A., Martinez, G.M., Mosher, W.D., Abma, J.C., Jones, J., 2005. Fertility, family planning, and reproductive health of U.S. women: data from the 2002 National Survey of Family Growth. National Center for Health Statistics. Vital Health Stat 23, 175.

Deneer, J.W., Sinnige, T.L., Seinen, W., Hermens, J.L.M., 1988a. The joint acute toxicity to Daphnia magna of industrial organic-chemicals at low concentrations. Aquat. Toxicol. 12, 33-38.

Deneer, J.W., Seinen, W., Hermens, J.L.M., 1988b. Growth of Daphnia magna exposed to mixtures of chemicals with diverse modes of action. Ecotoxicol. Environ. Saf. $15,72-77$.

Dimitrov, S., Dimitrova, N., Parkerton, T., Comber, M., Bonnell, M., Mekenyan, O., 2005. Baseline model for identifying the bioaccumulation potential of chemicals SAR QSAR Environ. Res. 16, 531-554.

Dimitrova, N., Dimitrov, S., Georgieva, D., Van Gestel, C.A.M., Hankard, P., Spurgeon, D., Li, H., Mekenyan, O., 2010. Elimination kinetic model for organic chemicals in earthworms. Sci. Total Environ. 408, 3787-3793.

Dondero, F., Negri, A., Boatti, L., Marsano, F., Mignone, F., Viarengo, A., 2010. Transcriptomic and proteomic effects of a neonicotinoid insecticide mixture in the marine mussel (Mytilus galloprovincialis, Lam.). Sci. Total Environ. 408, 3775-3786.

Dorne, J.L.C.M., 2007. Human variability in hepatic and renal elimination: implications for risk assessment. J. Appl. Toxicol. 27, 411-420.

Dorne, J.L.C.M., 2010. Metabolism, variability and risk assessment. Toxicology 268, $156-164$.

Drost, W., Backhaus, T., Vassilakaki, M., Grimme, L.H., 2003. Mixture toxicity of s-triazines to Lemna minor under conditions of simultaneous and sequential exposure. Fresen. Environ. Bull. 12, 601-607.

European Scientific Committees, 2011. Toxicity and Assessment of Chemica Mixtures - (Preliminary Opinion Approved for Public Consultation. Scientific Committee on Consumer Safety (SCCS), Scientific Committee on Health and Environmental Risks (SCHER), Scientific Committee on Emerging and Newly Identified Health Risks (SCENIHR)), DG Health \& Consumers, Directorate D: Health Systems and Products, Unit D5 - Risk Assessment, Brussels http://ec.europa.eu/health/scientific_committees/consultations/public consultations/scher_consultation_06_en.htm (accessed 07.01.12).

Faust, M., Altenburger, R., Backhaus, T., Blanck, H., Boedeker, W., Gramatica, P., Hamer, V., Scholze, M., Vighi, M., Grimme, L.H., 2001. Predicting the joint algal toxicity of multi-component s-triazine mixtures at low-effect concentrations of individual toxicants. Aquat. Toxicol. 56, 13-32.

Faust, M., Altenburger, R., Backhaus, T., Blanck, H., Boedeker, W., Gramatica, P., Hamer, V., Scholze, M., Vighi, M., Grimme, L.H., 2003. Joint algal toxicity of 16 dissimilarly acting chemicals is predictable by the concept of independent action. Aquat. Toxicol. 63, 43-63.

Fisker, K.V., Sørensen, J.G., Holmstrup, M., 2011. No costs on freeze tolerance in genetically copper adapted earthworm populations (Dendrobaena octaedra). Comp. Biochem. Physiol. C: Pharmacol. Toxicol. Endocrinol. 154, 204-207.

Gohlke, J.M., Thomas, R., Zhang, Y., Rosenstein, M.C., Davis, A.P., Murphy, C., Becker, K.G., Mattingly, C.J., Portier, C.J., 2009. Genetic and environmental pathways to complex diseases. BMC Syst. Biol. 3, 46, http://dx.doi.org/10.1186/1752-0509-3-46. 
Gomezeyles, J., Svendsen, C., Lister, L.J., Spurgeon, D.J., 2009. The measurement and modelling of mixture toxicity of imidacloprid and thiacloprid on the soil dwelling nematode Caenorhabditis elegans and the earthworm Eisenia fetida. Ecotoxicol. Environ. Saf. 72, 71-79.

Gordon, C.J., 2001. Role of environmental stress in the physiological response to chemical toxicants. Environ. Res. 92, 1-7.

Hering, D., Borja, A., Carstensen, J., Carvallo, L., Elliott, M., Feld, C.K., Heiskanen, A.S., Johnson, R.K., Moe, J., Pont, D., Solheim, A.L., Van den Bund, W., 2010. The European Water Framework Directive at the age of 10: a critical review of the achievements with recommendations for the future. Sci. Total Environ. 408, 4007-4019.

Hermens, J., Konemann, H., Leeuwangh, P., Musch, A., 1985. Quantitative structure activity relationships in aquatic toxicity studies of chemicals and complexmixtures of chemicals. Environ. Toxicol. Chem. 4, 273-279.

Heugens, E.H.W., Hendriks, A.J., Dekker, T., Van Straalen, N.M., Admiraal, W., 2001. A review of the effects of multiple stressors on aquatic organisms and analysis of uncertainty factors for use in risk assessment. Crit. Rev. Toxicol. 31, 247-284.

Hoegh-Guldberg, O., Mumby, P.J., Hooten, A.J., Steneck, R.S., Greenfield, P., Gomez, E., Harvell, C.D., Sale, P.F., Edwards, A.J., Caldeira, K., Knowlton, N., Eakin, C.M., Iglesias-Prieto, R., Muthiga, N., Bradbury, R.H., Dubi, A., Hatziolos, M.E., 2007. Coral reefs under rapid climate change and ocean acidification. Science 318, 1737-1742.

Højer, R., Bayley, M., Damgaard, C.F., Holmstrup, M., 2001. Stress synergy between drought and a common environmental contaminant: studies with the collembolan Folsomia candida. Global Change Biol. 7, 485-494.

Holmstrup, M., 1997. Drought tolerance in Folsomia candida (Collembola) after exposure to sublethal concentrations of three soil-polluting chemicals. Pedobiologia 41, 354-361.

Holmstrup, M., Bindesbol, A.-M., Oostingh, G.J., Duschl, A., Scheil, V., Koehler, H.R., Loureiro, S., Soares, A.M.V.M., Ferreira, A.L.G., Kienle, C., ' Gerhardt, A., Laskowski, R., Kramarz, P., Bayley, M., Svendsen, C., Spurgeon, D., 2010. Interactions between effects of environmental chemicals and natural stressors: a review. Sci. Total Environ. 408, 3746-3762.

Howard, G.J., Schlezinger, J.J., Hahn, M.E., Webster, T.F., 2010. Generalized concentration addition predicts joint effects of aryl hydrocarbon receptor agonists with partial agonists and competitive antagonists. Environ. Health Perspect. 118, 666-672.

Hope, B.K., 2005. Performing spatially and temporally explicit ecological exposure assessments involving multiple stressors. Hum. Ecol. Risk Assess. 11, 539-565.

Houben, J., 2011. Oehoe jaagt in centrum: populatie stadsduiven daalt. In: Dagblad De Limburger, 20 October 2011, Maastricht, The Netherlands (in Dutch).

Jager, T., Vandenbrouck, T., Baas, J., De Coen, W.M., Kooijman, S.A.L.M., 2010. A biology-based approach for mixture toxicity of multiple endpoints over the life cycle. Ecotoxicology 19, 351-361.

ILSI (International Life Sciences Institute), 2008. Cumulative and Aggregate Risk Evaluation System (CARES) V3.0. Downloaded from http://cares.ilsi.org (accessed 24.07.08).

IPCC, 2007. In: Pachauri, R.K., Reisinger, A. (Eds.), Climate Change 2007: Synthesis Report. Contribution of Working Groups I-III to the Fourth Assessment. Report of the Intergovernmental Panel on Climate Change. IPCC, Geneva, p. 104.

Jahnke, G.D., Iannucci, A.R., Scialli, A.R., Shelby, M.D., 2005. Center for the evaluation of risks to human reproduction - the first five years. Birth Defects Res. B Dev. Reprod. Toxicol. 74, 1-8.

Johnson, A.C., Nylén, P., Borg, E., Höglund, G., 1990. Sequence of exposure to noise and toluene can determine loss of auditory sensitivity in the rat. Acta Otolaryngol. 109, 34-40.

Jonker, M.J., Svendsen, C., Bedaux, J.J.M., Bongers, M., Kammenga, J.E., 2005. Significance testing of synergistic/antagonistic, dose level-dependent, or dose ratiodependent effects in mixture dose-response analysis. Environ. Toxicol. Chem. 24, 2701-2713.

Jørgensen, K., Ipsen, J.H., Mouritsen, O.G., Bennett, D., Zuckermann, M.J., 1991. The effects of density-fluctuations on the partitioning of foreign molecules into lipid bilayers - application to anesthetics and insecticides. Biochim. Biophys. Acta 1067, 241-253.

Kimizuka, G., Ohwada, H., Hayashi, Y., 1987. Co-carcinogenic effect of asbestos and benzo(a)pyrene. Acta Pathol. Jpn. 37, 465-474.

Kimizuka, G., Hayashi, Y., 1993. Combined effects of asbestos and smoking on hamster lung. In: Gibbs, G.W., Dunnigan, J., Kido, M., Higashi, T. (Eds.), Health Risks from Exposure to Mineral Fibres: An International Perspective. Captus University Publications, Ontario, Canada, pp. 254-263.

Kooijman, S.A.L.M., 2009. Dynamic Energy Budget theory for metabolic organization, 3rd edition. Cambridge University Press, UK.

Kozlov, M., Zvereva, E., 2007. Industrial barrens: extreme habitats created by nonferrous metallurgy. Rev. Environ. Sci. Biotechnol. 6, 231-259.

Kortenkamp, A., Backhaus, T., Faust, M., 2009. State of the Art on Mixture Toxicity. Report. Available at: http://ec.europa.eu/environment/chemicals/pdf/ report_Mixture\%20toxicity.pdf (accessed 06.01.12).

Laskowski, R., Bednarska, A.J., Kramarz, P.E., Loureiro, S., Scheil, V., Kudlek, J., Holmstrup, M., 2010. Interactions between toxic chemicals and natural environmental factors - a meta-analysis and case studies. Sci. Total Environ. 408, 3763-3774.

Leitte, A.M., Petrescu, C., Franck, U., Richter, M., Suciu, O., Ionovici, R., Herbarth, O., Schlink, U., 2009. Respiratory health, effects of ambient air pollution and its modification by air humidity in Drobeta-Turnu Severin, Romania. Sci. Total Environ. 407, 4004-4011.

Løkke, H., Ragas, A.M.J., Schüürmann, G., Spurgeon, D., Sørensen, P.B. (Eds.), 2010. Cumulative stressors - risk assessment of mixtures of chemicals and combinations of chemicals and natural stressors. Sci. Total Environ. 408, 3719-3963.

Loos, M., Ragas, A.M.J., Plasmeijer, R., Schipper, A.M., Hendriks, A.J., 2010b. EcoSpaCE: an object-oriented, spatially explicit model to assess the risk of multiple environmental stressors on terrestrial vertebrate populations. Sci. Total Environ. 408, 3908-3917.

Loos, M., Schipper, A.M., Schlink, U., Strebel, K., Ragas, A.M.J., 2010a. Receptororiented approaches in wildlife and human exposure modelling: a comparative study. Environ. Modell. Softw. 25, 369-382.

Loureiro, S., Svendsen, C., Ferreira, A.L.G., Pinheiro, C., Ribeiro, F., Soares, A.M.V.M., 2010. Toxicity of chemical mixtures to Daphnia magna: chemical modes of action and deviations from conceptual models. Environ. Toxicol. Chem. 29, 1716-1726.

Martin, H.L., Svendsen, C., Spurgeon, D.J., Lister, L.J., Gomezeyles, J., 2009. Measurement and modelling the combined toxicity of binary mixtures in the nematode Caenorhabditis elegans - a test of independent action. Environ. Toxicol. Chem. 28, 97-104.

Meek, M.E., Boobis, A.R., Crofton, K.M., Heinemeyer, G., Van Raaij, M., Vichers, C., 2011. Risk assessment of combined exposure to multiple chemicals: a WHO/IPCS framework. Regul. Toxicol. Pharmacol. 60, S1-S14, http://dx.doi.org/10.1016/j.yrtph.2011.03.010.

Mileson, B., Faustman, E., Olin, S., Ryan, P.B., Ferenc, S., Burke, T. (Eds.), 1999. A framework for cumulative risk assessment. International Life Sciences Institute. ILSI Press, Washington, DC, USA.

MSFD, 2008. Directive 2008/56/EC of the European Parliament and of the Council of 17 June 2008 establishing a framework for community action in the field of marine environmental policy. (Marine Strategy Framework Directive).

Munns Jr., W.R., 2006. Assessing risks to wildlife populations from multiple stressors: overview of the problem and research needs. Ecol. Soc. 11 (1) (article no. 23) http://www.ecologyandsociety.org/vol11/iss21/art23/

NRC (National Research Council), 1994. Science and Judgment in Risk Assessment. Committee on Risk Assessment of Hazardous Air Pollutants, Board on Environmental Studies and Toxicology, Commission on Life Sciences. National Academy Press, Washington, DC, USA.

Ogunbayo, O.A., Jensen, K.T., Michelangeli, F., 2007. The interaction of the brominated flame retardant: tetrabromobisphenol A with phospholipid membranes. Biochim. Biophys. Acta 1768, 1559-1566.

Oostingh, G.J., Schmittner, M., Ehart, A.K., Tischler, U., Duschl, A., 2008. A highthroughput screening method based on stably transformed human cells was used to determine the immunotoxic effects of fluoranthene and other PAHs. Toxicol. In Vitro 22, 1301-1310.

Oostingh, G.J., Wichmann, G., Schmittner, M., Lehmann, I., Duschl, A., 2009. The cytotoxic effects of the organophosphates chlorpyrifos and diazinon differ from their immunomodulating effects. J. Immunotoxicol. 6, 136-145.

PCCRARM (Presidential/Congressional Commission on Risk Assessment and Risk Management), 1997. Framework for Environmental Health Risk Management. Washington, DC, USA.

Price, P.S., Hollnagel, H.M., Zabik, J.M., 2009. Characterizing the noncancer toxicity of mixtures using concepts from the TTC and quantitative models of uncertainty in mixture toxicity. Risk Anal. 29, 1534-1548.

Ragas, A.M.J., Teuschler, L.K., Posthuma, L., Cowan, C., 2011a. Human and ecological risk assessment of chemical mixtures. In: Van Gestel, C.A.M., Jonker, M.J., Kammenga, J.E., Laskowski, R., Svendsen, C. (Eds.), Mixture Toxicity - Linking Approaches from Ecological and Human Toxicology. SETAC, CRC Press, New York, pp. 157-215.

Ragas, A.M.J., Oldenkamp, R., Preeker, N.L., Wernicke, J., Schlink, U., 2011b. Cumulative risk assessment of chemical exposures in urban environments. Environ. Int. 37, 872-881.

Rappaport, S.M., 2011. Implications of the exposome for exposure science. J. Expo. Anal. Environ. Epidemiol. 21, 5-9.

Ross, H.L.B., 1996. The interaction of chemical mixtures and their implications on water quality guidelines. Hons Thesis, University of Technology, Sydney, NSW, Australia. p. 167.

Ross, H.L.B., Warne, M.St.J., 1997. Most chemical mixtures have additive aquatic toxicity. In: Proceedings of the Third Annual Conference of the Australasian Society for Ecotoxicology, Brisbane, 17-19 July, 1997, p. 30.

Röder-Stolinski, C., Fischäder, G., Oostingh, G.J., Feltens, R., Kohse, F., von Bergen, M., Mörbt, N., Eder, K., Duschl, A., Lehmann, I., 2008a. Styrene induces an inflammatory response in human lung epithelial cells via oxidative stress and NF- $\mathrm{KB}$ activation. Toxicol. Appl. Pharmacol. 23, 241-247.

Röder-Stolinski, C., Fischäder, G., Oostingh, G.J., Eder, K., Duschl, A., Lehmann, I., 2008b. Chlorobenzene induces the NF-кB and p38 MAP kinase pathways in lung epithelial cells. Inhal. Toxicol. 20, 813-820.

Santore, R.C., Mathew, R., Paquin, P.R., Ditoro, D., 2002. Application of the biotic ligand model to predicting zinc toxicity to rainbow trout, fathead minnow, and Daphnia magna. Comp. Biochem. Physiol. C: Toxicol. Pharmacol. 133, 271-285.

Schlink, U., Fritz, G.J., Herbarth, O., Richter, M., 2002. Longitudinal modelling of respiratory symptoms in children. Int. J. Biometeorol. 47, 35-48.

Schlink, U., Ragas, A.M.J., 2011. Truncated Lévy flights and agenda-based mobility are useful for the assessment of personal human exposure. Environ. Pollut. 159, 2061-2070.

Skovlund, G., Damgaard, C., Bayley, M., Holmstrup, M., 2006. Does lipophilicity of toxic compounds determine effects on drought tolerance of the soil collembolan Folsomia candida? Environ. Pollut. 144, 808-815. 
Spurgeon, D.J., Jones, O.A.H., Dorne, J.L.C.M., Svendsen, C., Swain, S., Sturzenbaum, S.R., 2010. Systems toxicology approaches for understanding the joint effects of environmental chemical mixtures. Sci. Total Environ. 408, 3725-3734.

Spurgeon, D.J., Pohl, H.R., Loureiro, S., Løkke, H., Van Gestel, C.A.M., 2011. In: Van Gestel, C.A.M., Jonker, M.J., Kammenga, J.E., Laskowski, R., Svendsen, C. (Eds.), Mixture Toxicity - Linking Approaches from Ecological and Human Toxicology. SETAC, CRC Press, New York, pp. 1-45.

Svendsen, C., Jager, T., Haddad, S., Yang, R.S.H., Dorne, J.L.C.M., Broerse, M., Kramarz, P., 2011.In: Van Gestel, C.A.M., Jonker, M.J., Kammenga, J.E., Laskowski, R., Svendsen, C. (Eds.), Mixture Toxicity - Linking Approaches from Ecological and Human Toxicology. SETAC, CRC Press, New York, pp. 47-93.

Talent, L.G., 2005. Effect of temperature on toxicity of a natural pyrethrin pesticide to green anole lizards (Anolis carolinensis). Environ. Toxicol. Chem. 24, 3113-3116.

The Lifeline Group Inc., 2007. User's Manual. LifeLine ${ }^{\mathrm{TM}}$ Version 4.4. The LifeLine Group, Annandale, VA, USA, p. 117.

Thomas, R., Gohlke, J.M., Stopper, G.F., Parham, F.M., Portier, C.J., 2009. Choosing the right path: enhancement of biologically relevant sets of genes or proteins using pathway structure. Genome Biol. 10, R44, http://dx.doi.org/10.1186/gb-2009-10-4-r44.

Topping, C.J., Hansen, T.S., Jensen, T.S., Jepsen, J.U., Nikolajsen, F., Odderskær, P., 2003. ALMaSS, an agent-based model for animals in temperate European landscapes. Ecol. Modell. 167, 65-82.

Trasande, L., Landrigan, P.J., 2004. The National Children's Study: a critical national investment. Environ. Health Perspect. 112, A789-A790.

US EPA (U.S. Environmental Protection Agency), 2000. Supplementary guidance for conducting health risk assessment of chemical mixtures. EPA/630/R-00/002. ORD/NCEA. Cincinnati, Ohio.

US EPA (U.S. Environmental Protection Agency), 2003. Framework for Cumulative Risk Assessment. United States Environmental Protection Agency, Risk Assessment Forum, Washington, DC, USA.

US EPA (U.S. Environmental Protection Agency), 2006a. Total Risk Integrated Methodology (TRIM) Air Pollutants Exposure Model Documentation (TRIM. Expo/APEX, Version 4) Volume I: User's Guide. Office of Air Quality Planning and Standards, Durham, NC, USA, p. 86.

US EPA (U.S. Environmental Protection Agency), 2006b. Total Risk Integrated Methodology (TRIM) Air Pollutants Exposure Model Documentation (TRIM. Expo/APEX, Version 4) Volume II: Technical Support Document. Office of Air Quality Planning and Standards, Durham, NC, USA, p. 92.

US EPA (U.S. Environmental Protection Agency), 2007. Concepts, methods and data sources for cumulative health risk assessment of multiple chemicals, exposures and effects: a resource document (EPA/600/R-06/014F). In: National Center for Environmental Assessment, Office of Research and Development. US Environmental Protection Agency, Cincinnati, Ohio.
Vallotton, N., Eggen, R.I.L., Chèvre, N., 2009. Effect of sequential isoproturon pulse exposure on Scenedesmus vacuolatus. Arch. Environ. Contam. Toxicol. 56, 442-449.

Van Gestel, C.A.M., Jonker, M.J., Kammenga, J.E., Laskowski, R., Svendsen, C. (Eds.) 2010. Mixture Toxicity: Linking Approaches from Ecological and Human Toxicology. SETAC, CRC Press, Boca Raton, p. 280.

Van Wezel, A.P., Cornelissen, G., Van Miltenburg, J.K., Opperhuizen, A., 1996. Membrane burdens of chlorinated benzenes lower the main phase transition temperature in dipalmitoyl-phosphatidylcholine vesicles: implications for toxicity by narcotic chemicals. Environ. Toxicol. Chem. 15, 203-212.

Vandenbrouck, T., Soetaert, A., Van der Ven, K., Blust, R., De Coen, W., 2009. Nicke and binary metal mixture responses in Daphnia magna: Molecular fingerprints and (sub)organismal effects. Aquat. Toxicol. 92, 18-29.

Warne, M.S., Hawker, D.W. 1995. The number of components in a mixture determines whether synergistic and antagonistic or additive toxicity predominate: the funnel hypothesis. Ecotoxicol. Environ. Saf. 31, 23-28.

Warne, M.S.J., 2003. A review of the ecotoxicity of mixtures, approaches to, and recommendations for, their management. In: Langley, A., Gilbey, M., Kennedy, B. (Eds.), Proceedings of the Fifth National Workshop on the Assessment of Site Contamination. National Environment Protection Council Service Corporation, Adelaide, SA.

Weber, R.E., De Zwaan, A., Bang, A., 1992. Interactive effects of ambient copper and anoxic, temperature and salinity stress on survival and hemolymph and muscle tissue osmotic effectors in Mytilus edulis. J. Exp. Mar. Biol. Ecol. 159, 135-156.

Wharton, D.A., 2002. Life at the Limits. Cambridge University Press, Cambridge, p. 307.

WHO (World Health Organization), 2009. Assessment of Combined Exposures to Multiple Chemicals: Report of a WHO/IPCS International Workshop. International Programme on Chemical Safety (IPCS), Inter-Organization Programme for the Sound Management of Chemicals (IOMC), Geneva.

Zartarian, V.G., Xue, J., Ozkaynak, H.A., Dang, W., Glen, G., Smith, L., Stallings, C., 2006. A probabilistic arsenic exposure assessment for children who contact Chromated Copper Arsenate (CCA)-treated playsets and decks, part 1 : model methodology, variability results, and model evaluation. Risk Anal. 26 515-531.

Zartarian, V.G., Glen, G., Smith, L., Xue, J., 2007. Stochastic Human Exposure and Dose Simulation Model for Multimedia, Multipathway Chemicals. SHEDS-Multimedia Model version 3. Technical Manual, United States Environmental Protection Agency, Presented to the USEPA Office of Pesticide Program's FIFRA Scientific Advisory Panel, August 14-15, 2007. Available at http://www.epa.gov/scipoly/sap/meetings/2007/august/sheds_techmanual_06 -14.pdf 